\title{
Impact of Clay Mineralogy on Stabilization of Soil Organic Carbon for Long-Term Carbon Sequestration
}

\author{
Ravi Kumar Meena ${ }^{1 *}$, Anil Kumar Verma ${ }^{1}$, Chiranjeev Kumawat ${ }^{1}$ \\ Brijesh Yadav', Atul B. Pawar' ${ }^{1}$ and V.K. Trivedi ${ }^{1}$ \\ ${ }^{1}$ Division of Soil Science and Agricultural Chemistry, ${ }^{2}$ Division of Agricultural Physics, Indian \\ Agricultural Research Institute, New Delhi - 110012, India \\ *Corresponding author
}

\author{
A B S T R A C T
}

\section{Keywords}

Stabilization, Pyrophyllite, Hydroxylated, Temperature.

Article Info

Accepted:

19 April 2017

Available Online:

10 May 2017
One of the largest sinks of organic carbon on the global scale is the organic matter stored in soils, it contains about $1500 \mathrm{Gt} \mathrm{C}$ in the top one meter. Changes in the size and the turnover rate of the soil carbon pools could possibly have an effect on the atmospheric $\mathrm{CO} 2$ concentration and the global climate. Stabilization of soil organic C (SOC) is pre-requisite for long-term C sequestration to mitigate climate change. Stabilization of SOC means the decrease in the potential loss of organic $\mathrm{C}$ by microbial respiration, erosion or leaching. Sorption to mineral surfaces is considered to be the most effective mechanism that protects SOC against microbial degradation. The stabilization of SOC is not only influenced by the amount (i.e., soil texture) of but also the type of clays present. The sandy clay loam soils of Pattambi, Kerala stabilized more silt+clay protected $\mathrm{C}$ than sandy loam soil of Bhubaneswar, Odisha. The smectic clays are more potent in accumulation and sequestration of SOC in black cotton soils of India. Sorption is influenced by the chemical properties of a mineral, mainly the surface chemistry, which includes the surface structure of the mineral, and is also influenced by the physical properties, e.g. the specific surface area (SSA) and the porosity. Soil organic matter sorption seems to increase with increasing specific surface area (SSA) of soil minerals. SSA in soils can be related to the oxide content. Ligand exchange occurs mostly in acid soils and soils which are rich in oxides. Perhaps ligand exchange is more relevant in subsoils, because of the smaller surface loadings. The bonds by ligand exchange are very strong, they are able to outlast over 100 years. In neutral and alkaline soils mostly $\mathrm{Ca} 2+$ und $\mathrm{Mg} 2+$ occur, whereas in acid soils additionally $\mathrm{Fe} 3+$ and $\mathrm{Al} 3+$ form cation bridges with $\mathrm{SOM}$ by electrostatic bonding. The coordination complexes of the $\mathrm{Fe} 3+$ und $\mathrm{Al} 3+$ ions are considerably stronger in comparison to those with $\mathrm{Ca} 2+$. Ligand exchange is considered to be the most efficient binding mechanism at lower $\mathrm{pH}$ values on porous clay minerals. As $\mathrm{pH}$ increases, adsorption of SOM to mineral surfaces generally decreases. The $\mathrm{pH}$ affects the surface charge of variable-charge minerals, e.g. Fe and $\mathrm{Al}$ hydroxides. On hydroxylated surfaces, the net surface charge becomes increasingly negative as $\mathrm{pH}$ increases. Increase in temperature will cause reduction in stabilization due to desorptive effect of greater affinity molecules from soil mineral surfaces. Mineral characteristic exerts control on top soil organic carbon pool, such information is crucial to assess the site specific potential of afforestation to mitigate global warming. So this provides scope for development of a method that can predict capacity of different soils to stabilize the SOM. 


\section{Introduction}

In 1992, the Kyoto Protocol on climate change demanded the fundamental understanding of the stabilization of carbon in soils. The reason for this lies in the fact that one of the largest sinks of organic carbon on the global scale is the organic matter stored in soils (Kalbitz et al., 2005). Changes in the size and the turnover rate of the soil carbon pools could possibly have an effect on the atmospheric $\mathrm{CO} 2$ concentration and the global climate (Lützow et al., 2006). Although the ability of the soil to store organic matter and to prevent it (partly) from mineralization to $\mathrm{CO} 2$ has received growing interest in the last years, the mechanisms for carbon stabilization are still not entirely clear, and the potential of the soil for carbon stabilization is unknown (Kaiser and Guggenberger, 2003).

Stabilization of soil organic C (SOC) is prerequisite for long-term $\mathrm{C}$ sequestration to mitigate climate change. Stabilization of SOC means the decrease in the potential loss of organic $\mathrm{C}$ by microbial respiration, erosion or leaching (Sollins et al., 1996). More than 45\% of TOC is in the form of stabilized SOC (Lewandowski et al., 2002).

Sorption to mineral surfaces is considered to be the most effective mechanism that protects SOC against microbial degradation (Mikutta et al., 2007). The stabilization of SOC is not only influenced by the amount (i.e., soil texture) of but also the type of clays present. The sandy clay loam soils of Pattambi, Kerala stabilized more silt+clay protected $\mathrm{C}$ than sandy loam soil of Bhubaneswar, Odisha (Sukumaran et al., 2016). The smectic clays are more potent in accumulation and sequestration of SOC in black cotton soils of India (Bhattacharyya et al., 2005). Sorption is influenced by the chemical properties of a mineral, mainly the surface chemistry, which includes the surface structure of the mineral, and is also influenced by the physical properties, e.g. the specific surface area (SSA) and the porosity. Soil organic matter sorption seems to increase with increasing specific surface area (SSA) of soil minerals (Kahle et al., 2004). SSA in soils can be related to the oxide content (Kleber et al., 2005).

Mikutta et al., (2007) approximated the contribution of binding mechanisms between forest floor organic matter and goethite, pyrophyllite and vermiculite at $\mathrm{pH}$ 4.Ligand exchange occur mostly in acid soils and soils which are rich in oxides. Perhaps ligand exchange is more relevant in subsoils, because of the smaller surface loadings. The bonds by ligand exchange are very strong, they are able to outlast over 100 years (Lützow et al., 2006). In neutral and alkaline soils mostly $\mathrm{Ca} 2+$ und $\mathrm{Mg} 2+$ occur, whereas in acid soils additionally $\mathrm{Fe} 3+$ and $\mathrm{Al} 3+$ form cation bridges with SOM by electrostatic bonding. The coordination complexes of the $\mathrm{Fe} 3+$ und $\mathrm{Al} 3+$ ions are considerably stronger in comparison to those with $\mathrm{Ca} 2+$ (Lützow et al., 2006).

\section{Materials and Methods}

\section{Control on stabilization}

Potential controls on stabilization and destabilization are diagrammed in Fig. 1. This figure focuses specifically on stabilization as they relate to respiration.

It has been drawn with stabilization as separate circles, each divided into three parts: change in recalcitrance, change in interactions, and change in accessibility (Cheshire et al., 1974; Ladd et al., 1993).

Recalcitrance comprises molecular-level characteristics of organic substances, including elemental composition, presence of functional groups, and molecular conformation, that influence their degradation 
by microbes and enzymes. Interaction of soil organic $\mathrm{C}$ with other substances can increase stabilization with respect to microbial respiration. Through precipitation, sorption, and complexion reactions, organics may interact with other organics or with inorganic materials, such as clay surfaces or dissolved aluminum and iron, thereby lowering their potential to be acted upon by microorganisms and their extracellular enzymes. The reactions are influenced by the chemical environment and by the surface properties of clay minerals.

\section{Mechanisms of soil organic matter stabilization (Protection)}

\section{Chemical stabilization}

Through chemical or physio-chemical binding between SOM and soil minerals. SOM associated with the $<20 \mu \mathrm{m}$ is better protected against decomposition. Protection determined by extent of adsorption and nature of bonding, if bonding is strong like ligand exchange stabilization also strong. It also depends on the surface chemistry of minerals also.

\section{Physical stabilization}

Stabilization of SOM from microbial decomposition through occlusion within macro- and micro-aggregates and Inaccessibility of substrate to microbes and enzymes, $50 \%$ of organic matter is protected by this mechanism (Elliott et al., 1996). It depends on the formation of micro aggregate and micro aggregate stability. It may vary with intercultural operations like tillage puddling etc.

\section{Biochemical stabilization}

Protection of SOM from microbial decomposition due to the complex chemical composition of the organic matter (e.g. recalcitrant compounds such as lignin and polyphenols), this complex chemical composition can be an inherent property of plant residue, or be acquired during decomposition.

\section{Stabilization of $\mathrm{OM}$ in relation with soil texture}

The capacity to protect organic carbon (C) and nitrogen $(\mathrm{N})$ in fine textured soils is higher than coarse textured soils with similar addition of organic inputs (Hassink et al., 1997; Jenkinson, 1988). Association with silt and clay particles can be attributed as one of the main factors responsible for the physical protection of organic carbon and nitrogen in soil (Theng, 1979). In fine soil fractions, the $\mathrm{C}$ and $\mathrm{N}$ associated is largely affected by soil texture, unlike in large fractions, where it is mainly regulated by organic inputs rather than soil texture (Christensen, 1992, Garwood et al., 1972). Most of this organic matter exists in the colloidal fraction of the soil but larger particles also have organic coatings.

The study done by suvana et al., (2016), they found that the $\mathrm{C}$ and $\mathrm{N}$ carrying capacity in the silt+clayfraction of Alfisol was greatly influenced by soil texture. Alfisol of Pattambi having sandy clay loam in texture stabilized more amount of $\mathrm{C}$ and $\mathrm{N}$ than Alfisol of Bhubaneswar having sandy loam in texture (fig.3.)

Textural differences also influence stabilization. The soil with more finer fraction stabilize more organic carbon than that of courser soil. Chemically stabilized organic carbon mainly occurs through organo mineral interaction with clay minerals and organic matter.

\section{Bonding mechanism in organo-mineral complex}

Different binding mechanisms can occur between soil organic matter and mineral surfaces depending on the properties of both 
the mineral surface and the soil organic matter.

\section{Ligand exchange}

An important mechanism for the formation of strong complexes of organic matter and mineral surfaces is anion exchange between singly coordinated $\mathrm{OH}$ groups on mineral surfaces, carboxyl groups $(\mathrm{COOH})$ and phenolic $\mathrm{OH}$ groups of the soil organic matter, e.g. Fe-O-C bonds (Lützow et al., 2006). Anions possess one or more atoms with a lone pair of electrons and thus can act as the donor in a coordinate bond (Cornell and Schwertmann, 2003).

\section{Bridges of polyvalent cations}

Organic anions are normally pushed away from negatively charged surfaces in soils. Bindings can only occur if there are polyvalent cations, which neutralize the mineral surface by acting like a bridge and adjusting the charge of the negatively charged mineral surface as well as the charge of the acidic functional group of the organic matter (COO-). In neutral and alkaline soils mostly $\mathrm{Ca} 2+$ und $\mathrm{Mg} 2+$ occur, whereas in acid soils additionally $\mathrm{Fe} 3+$ and $\mathrm{Al} 3+$ form cation bridges. The coordination complexes of the $\mathrm{Fe} 3+$ und $\mathrm{Al} 3+$ ions are considerably stronger in comparison to those with $\mathrm{Ca} 2+$ (Lützow et al., 2006).

\section{Weak interactions}

\section{Van der Waals forces}

Van der Waals forces are electrostatic forces caused by a temporarily fluctuating dipole moment arising from a brief shift of orbital electrons to one side of an atom or molecule which creates a similar shift in adjacent atoms or molecules (Lützow et al., 2006). Van der Waals forces are nonspecific interactions which can form between any kinds of molecules, no matter what chemical structure they have (Schwarzenbach et al., 2003).

\section{Hydrophobic interactions}

Non-polar residues are excluded from water by entropy-related interactions to force the non-polar groups together.

Hydrophobic interactions become more favourable at low $\mathrm{pH}$ due to the protonation of hydroxyl and carboxyl groups of $\mathrm{OM}$ and the suppressed ionisation of the carboxyl groups (Lützow et al., 2006).

\section{H-Bonding}

A hydrogen atom with a positive partial charge interacts with partially negative charged $\mathrm{N}$ or $\mathrm{O}$ atoms (Lützow et al., 2006). Hydrogen does not possess any inner electrons isolating the nucleus from the bonding electrons, it consists only of one proton. If hydrogen bonds with highly electronegative atoms, the bonding electrons are drawn to the electronegative atom, leaving the proton exposed at the outer end of the covalent bond. This proton can now attract another electron-rich center and form a hydrogen bond (Schwarzenbach et al., 2003).

$-\mathrm{X} \delta--\mathrm{H} \delta+\ldots: \mathrm{Y} \delta--\mathrm{X}, \mathrm{Y}=\mathrm{N}, \mathrm{O}, \ldots$

Weak interaction occurs in all soils, no preference was found (Lützow et al., 2006).

\section{Models of organo-mineralinteraction}

Decades ago, earth scientists acknowledged the ability of mineral particles to protect soil organicmatter (SOM) from biological attack (Jung, 1943; Allison et al., 1949). In temperate, cultivated soils, $50-75 \%$ of SOM exists within clay-sized organomineral particles (Christensen, 2001), and numerous 
researchers have reported positive correlations between the contents of mineral particles and carbon in soils (Körschens, 1980; Nichols, 1984; Burke et al., 1989; Mayer and Xing, 2001).

\section{Wershaw bilayer model}

The soluble mixtures of organic molecules representing a significant fraction of SOM can form organized structures called micelles within aqueous solution, structures that consist of hydrophilic exterior regions that shield hydrophobic interiors from contact with water molecules (von Wandruszka, 1998). Because amphiphilic molecules are requisite to the formation of micelles, the ability of SOM components to form these structures suggests that many of these molecules are amphiphilic. Significant to this insight, Wershaw (1993) previously developed a bilayer model of organo-mineral interactions (Fig.4.) that sharply contrasted with the traditional view of organo-mineral interactions (Stevenson 1985), which were visualized as associations of large, multifunctional polymers with mineral surfaces via a broad range of bonding mechanisms (Stevenson, 1985; Leinweber and Schulten, 1998). Further, Wershaw and Pinckney (1980) postulated that decayed organic materials are often bound to clay surfaces by amino acids or proteins, based on the observation that deamination of organomineral complexes with nitrous acid released organic materials from the clay.

\section{Zonal model}

The zonal structure of organo-mineral associations (Fig.5), based on the amphiphilicity of SOM fragments, and the intimate involvement of proteinaceous compounds in stable organo-mineral associations, as defined here, a zonal structure is formed when the organic matter attached to a mineral surface is segregated into more than one layer or zone of molecules, such that not all adsorbed molecules are in contact with the mineral surface. Assuming such a zonal structure, we are able to account simultaneously for a number of phenomena observed in soils and sediments.

\section{Micro aggregate model}

Organo-mineral interactions manifest themselves primarily as organic surface coatings on clay particles, which can be considered an aggregate when sandwiched between two clay particles (Fig. 6). From that perspective, one can ask whether the interaction with mineral surfaces or the protection by its location between minerals confers more stability to the organic matter.

A spatial distinction of organic matter forms becomes important to distinguish organic coatings that bear very different chemical characteristics than organic debris in pores (Kinyangi et al., 2006). Interactions between microbial metabolites and mineral surfaces are important in initiating $\mathrm{OM}$ stabilization and that physical occlusion within micro aggregates is a secondary stabilization process

\section{Mineral properties controlling stabilization}

\section{Clay mineral type}

From the study of (Bhattacharyya et al., 1993, 1997; Shirsath et al., 2001) they found that the type of clay is also important in stabilization more than the clay percentage. They have studied two soil from same order having different clay percentage.SOC content (Table. 4) and smectite content of Alfisols of Satpura (P3) and that of the Western Ghats (P6) are compared. Even under forests, the Alfisols of the Western Ghats (P6) had lesser amount of SOC due to lower amount of smectite than the Alfisols of the Satpura (P3) under agriculture. 


\section{Presence of amorphous oxide}

Effects of goethite coatings on kaolinite, illite, and smectite on DOC sorption, the effect of coating illitic clay with different hydrous iron oxides (haematite, goethite, ferrihydrite) on DOC sorption was studied in another experiment. Organic matter extracted from dried medic (Medicago truncatula cv. Praggio) shoot residue was reacted with minerals at DOC concentrations ranging from 0 to $200 \mathrm{mg} \mathrm{C} \mathrm{L}-1$ at $\mathrm{pH}$ 6.0. The maximum adsorption capacity (Qmax) of phyllosilicate clays, as determined from fits to the Langmuir equation, increased in the order kaolinite $b$ illite $b$ smectite on a mass basis and illite $b$ smectite $b$ kaolinite on a surface area basis.

The sorption capacity of kaolinitic clay increased significantly with goethite coating The presence of goethite reduced desorption from kaolinitic clays but did not influence desorption from illitic and smectitic clays. The results suggest that interactions of hydrous iron oxides and phyllosilicate clays can modify DOC sorption and desorption, probably by affecting the surface charges and SSA. Study done by Kleber et al., (2005) also found that amorphous iron and aluminium oxide better co relate with that crystalline oxides. Crystalline minerals exhibit smaller SSA values and hydroxyl site densities than poorly crystalline minerals (Bracewell et al., 1970), and thus are less efficient in forming organo-mineral associations than poorly crystalline minerals. Consequently, crystalline Fe oxides need to be present in substantial amounts (>45 g/kg soil; Figure 8) to protect similar proportions of $\mathrm{OM}$ as samples containing moderate amounts of poorly crystalline minerals.

\section{Specific surface area (SSA)}

The organic carbon content of soil is positively related to the specific surface area (SSA), but large amounts of organic matter in soil result in reduced SSA as determined by applying the Brunauer- Emmett-Teller (BET) equation to the adsorption of $\mathrm{N} 2$.

\section{Results and Discussion}

\section{Factors influencing stabilization}

Temperature: The response of soil organic matter (OM) decomposition to increasing temperature is a critical aspect of ecosystem responses to global change. The impacts of climate warming on decomposition dynamics have not been resolved due to apparently contradictory results from field and lab experiments, most of which has focused on labile carbon with short turnover times. But the majority of total soil carbon stocks are comprised of organic carbon with turnover times of decades to centuries. Understanding the response of these carbon pools to climate change is essential for forecasting longer-term changes in soil carbon storage.

\section{Effect of pH}

Effects of the $\mathrm{pH}$ variation on the complexation of humic substances by dried clay-humus systems were investigated. The amounts of FA (fulvic acid) fixed, when FA solutions at various $\mathrm{pH}$ values were complexed with Ca-montmorillonite, Ca-illite and Ca-kaolinite, were determined. The amounts of FA extractable at different $\mathrm{pH}$ values from FA@H 7.0)-clay-complexes were determined; the variation of extraction of HA (humic acid) at two different temperatures, from Ca-clay-HA complexes were also studied. Mainly electrostatic; water-bridges may exist between such links, even when the complexes are dry.

\section{Type of organic matter added}

Mineralization of DOC is decreased with increase in degree of decomposition of the parent solid material. Experiment done by 
Karsten et al., (2005) they found that the stabilization of decomposed organic matter is more than that of fresh organic matter. They studied the mineralization rate of fresh maize solution, organic matter extracted from Oi layer of soil and organic matter extracted from Oa layer.

After adsorbtion of these OM to the clay mineral they found that the $\mathrm{OM}$ from the $\mathrm{Oa}$ layer is more stabilized than that of fresh maize solution. Finding the mean residence time they found that $\mathrm{Oa}$ adsorbed $\mathrm{OM}$ have a MRT of 95 year (Table 10) but the adsorbed fresh organic matter have MRT only 1.5 year.

\section{Different land use}

Study done by Zhang et al., 2016 on different land use of crop land grass land and forest land. They found stabilization is vary with different land use.

SOC stabilization in grasslands is likely due primarily to physical protection by macroand micro-aggregates. In cropland, medium and coarse soils appeared to be of equal importance in SOC stabilization as fine soil. Organic C stabilization by clay particles was more important for SOC accumulation in forest soil.

MOC-(Mineral-Grasslands differ from forests and croplands in having a larger proportion of underground biomass and fine roots, which facilitate the formation of aggregates (O'Brien and Jastrow, 2013). Thus, SOC stabilization in grasslands is likely due primarily to physical protection by macro- and microaggregates.

\section{Effect of climate}

Study done by Zhang et al., 2016 in china they have found that climate have a greater influence on stabilization by improving the mineralization. When they compared MOC $<53 \mathrm{~mm} / \mathrm{TSOC}$ ratios across climatic regions (Fig. 13), they found evidence suggesting that climate was a major factor in regulating MOC/TSOC ratios.

Cropland soils in the humid typical-temperate zones (mainly in northern China) and the subtropical zones (southern China), MOC <53 $\mathrm{mm} / \mathrm{TSOC}$ ratios were 0.77 and 0.74 , respectively.

\section{Effect of soil type}

In all six soil types across the three land uses, MOC $<53 \mathrm{~mm}$ was positively correlated with TSOC.

The significant linear regressions indicated that $\mathrm{MOC}<53 \mathrm{~mm} / \mathrm{TSOC}$ ratios were relatively stable at a given TSOC range. Because these soils were categorized based on intrinsic differences in soil mineral content, the significant partial coefficient of TSOC accumulation to $\mathrm{MOC}<53 \mathrm{~mm}$ (i.e., the slope of the regression) demonstrated that differing responses to organic $\mathrm{C}$ among soil types was likely due to their mineral content (Table 11). For example, ultisol is richer in iron and aluminum (oxy) hydroxides than the other five soil groups (Wagai et al., 2013).

The large surface area and absorption capacity of iron and aluminum (oxy) hydroxides enable ultisols to exhibit more organo-mineral binding (Spielvogel et al., 2008; Wiseman and Püttmann, 2006).

A relatively high $\mathrm{MOC} / \mathrm{TSOC}$ ratio was also found in mollisols, which were mainly distributed in the temperate regions of northeast China. This soil type has been found to possess a higher percentage of organic $\mathrm{C}$ than other soils in the same area, despite having similar fine-fraction proportions (Zhao et al., 2006). 
Fig.1 Long-term effect of manuring and fertilization on clay + silt protected $\mathrm{C}$ in two Alfisols with different texture

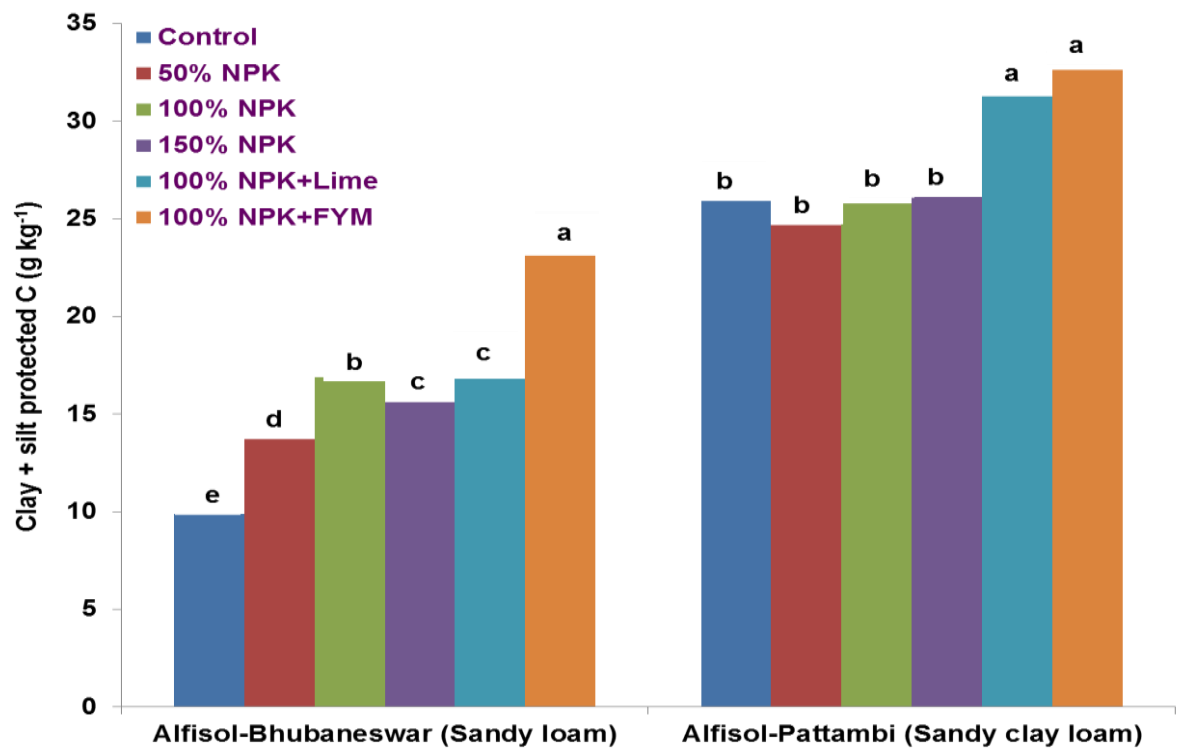

Fig.2 Effect of climate on MOC - stabilization

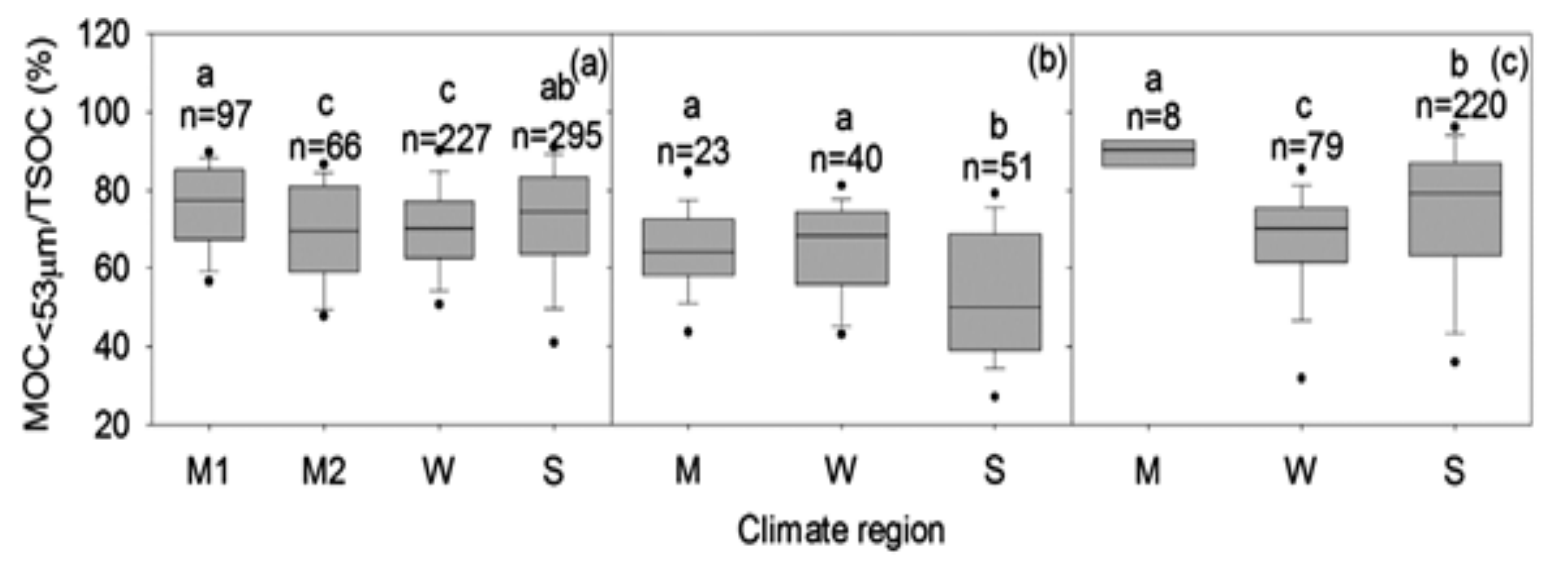


Fig.4 Temperature effect of Surface area

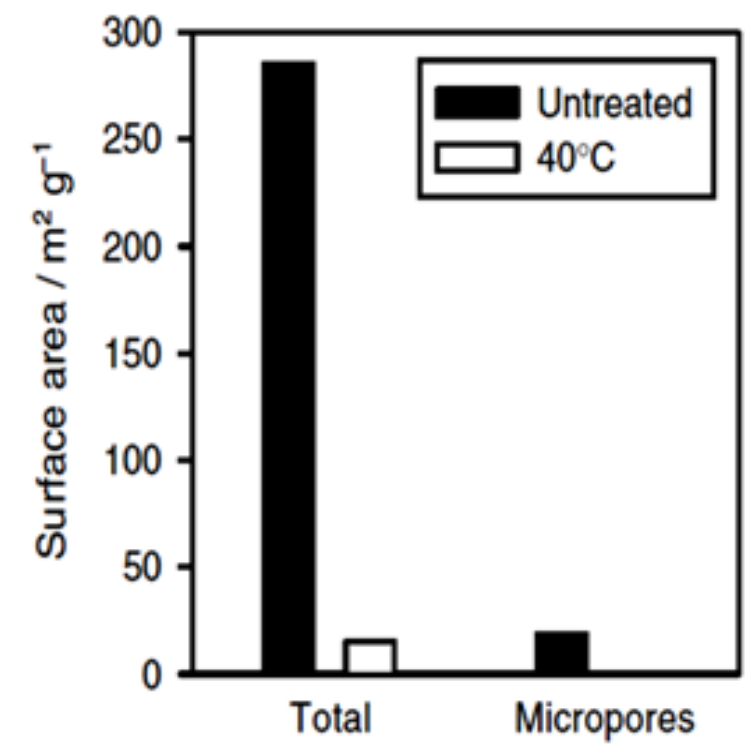

Fig.3 Temperature effect on micropore surface area of ferrihydrite and OC sorption

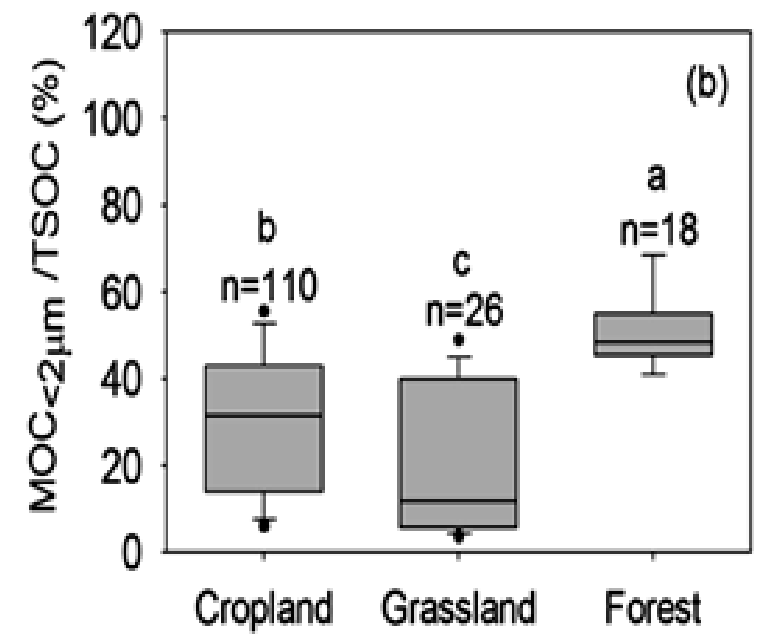




\section{Effects of management}

Study found significant, positive linear correlations between $\mathrm{MOC}<53 \mathrm{~mm}$ and TSOC in cropland, with MOC/TSOC ratios of $0.58 \mathrm{e} 0.75$ (Table 12). Agricultural management can alter microenvironment conditions in soil and consequently influence SOC decomposition and stabilization, processes that are further complicated by practices such as routine fertilization and drying rewetting cycles, which strongly affect soil nutrient cycling (Jarvis et al., 2007; Pan et al., 2009). In this study, average MOC $<53$ $\mathrm{mm} / \mathrm{TSOC}$ ratios were similar in the monoand double-cropping systems (0.70 and 0.73$)$, although more variation was observed in the double-cropping than in the monocropping soils. These results demonstrate that different cropping practices were unlikely to change the way that gross organic $\mathrm{C}$ inputs were partitioned into different SOC pools. Fertilization greatly affects MOC/TSOC ratios because it alters the quantity and quality of organic $\mathrm{C}$ inputs. We found that under mineral fertilizer applications, the average MOC $<53 \mathrm{~mm} / \mathrm{TSOC}$ ratios were much higher in paddy fields (0.75) than in other agricultural land uses $(0.58 \mathrm{e} 0.68)$. However, under organic fertilizer applications, the average MOC $<53 \mathrm{~mm} / \mathrm{TSOC}$ ratio in uplands was significantly higher than in paddy fields (Table 12). With mineral fertilizers application, soils in both upland and paddy field were far from saturation (Zhang et al., $2012,2010)$. This difference may be due to the frequent drying-rewetting procedures in paddy fields, which could enhance the stabilization of organic $\mathrm{C}$ by soil minerals (Cosentino et al., 2006; Muhr et al., 2010). Moreover, the large absorption capacity of iron and aluminum (oxy) hydroxides in paddy soils likely caused more organo-mineral binding, also increasing organic $\mathrm{C}$ stabilization. Finally, the strong influence of fertilization on MOC/TSOC ratios is further supported by the reversal we found when organic fertilizer was used.

It is concluded that the clay mineral type instead of clay content is a more important factor in accumulation and sequestration of SOC. Presence of poly-valent cation and amorphous oxides can influence mineral associated stabilization. Quality of organic matter and nature of organic compound can be influence stabilization of organic matter on mineral surface in soil. Better understanding of stabilization mechanism is important to assess site-specific potentials of afforestation to mitigate global warming. Management of stabilization of soil organic matter through mineral interaction is very difficult.

\section{References}

Bhattacharyya, T., Pal, D.K., Chandran, P., and Ray, S.K. 2005. Land-use, clay mineral type and organic carbon content in two Mollisols-Alfisols-Vertisols catenary sequences of tropical India. Clay Res., 24: 105-122.

Cai, A., Feng, W., Zhang, W., \& Xu, M. 2016. Climate, soil texture, and soil types affect the contributions of fine-fractionstabilized carbon to total soil organic carbon in different land uses across China. J. Environ. Manage., 172: 2-9.

Conant, R.T., Ryan, M.G., Agren, G.I., Birge, H.E., Davidson, E.A., Eliasson, P.E., and Hyvönen, R. 2011. Temperature and soil organic matter decomposition ratessynthesis of current knowledge and a way forward. Global Change Biol., 17(11): 3392-3404.

Eusterhues, K., Rumpel, C., Kleber, M., \& Kögel-Knabner, I. 2003. Stabilisation of soil organic matter by interactions with minerals as revealed by mineral dissolution and oxidative degradation. Organic Geochem, 34(12): 1591-1600.

Feng, W., Plante, A.F., \& Six, J. 2013. Improving estimates of maximal organic 
carbon stabilization by fine soil particles. Biogeochem., 112(1-3): 81-93.

Kleber, M., Sollins, P., \& Sutton, R. 2007. A conceptual model of organo-mineral interactions in soils: self-assembly of organic molecular fragments into zonal structures on mineral surfaces. Biogeochem., 85(1): 9-24.

Mikutta, R., Mikutta, C., Kalbitz, K., Scheel, T., Kaiser, K., and Jahn, R. 2007. Biodegradation of forest floor organic matter bound to minerals via different binding mechanisms. Geochimica et Cosmochimica Acta, 71(10): 2569-2590.

Saidy, A.R., Smernik, R.J., Baldock, J.A., Kaiser, K., Sanderman, J., \& Macdonald, L.M. 2012. Effects of clay mineralogy and hydrous iron oxides on labile organic carbon stabilisation. Geoderma, 173: 104110.

Wiseman, C.L.S., \& Püttmann, W. 2006. Interactions between mineral phases in the preservation of soil organic matter. Geoderma, 134(1): 109-118.

\section{How to cite this article:}

Ravi Kumar Meena, Anil Kumar Verma, Chiranjeev Kumawat, Brijesh Yadav, Atul B. Pawar and Trivedi V.K. 2017. Impact of Clay Mineralogy on Stabilization of Soil Organic Carbon for LongTerm Carbon Sequestration. Int.J.Curr.Microbiol.App.Sci. 6(5): 2157-2167. doi: https://doi.org/10.20546/ijcmas.2017.605.242 